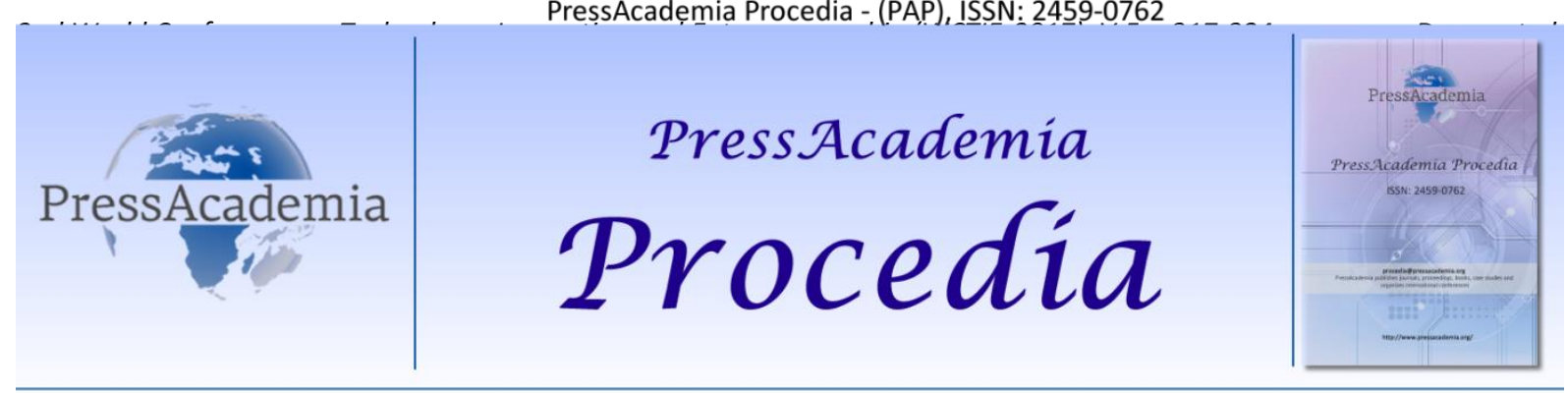

2nd World Conference on Technology, Innovation and Entrepreneurship

May 12-14, 2017, Istanbul, Turkey. Edited by Sefer Şener

\title{
ERGONOMIC RISK ASSESSMENT OF MANUAL MATERIAL HANDLING AT AN AUTOMOTIVE MANUFACTURING COMPANY
}

\author{
DOI: 10.17261/Pressacademia.2017.606 \\ PAP-WCTIE-V.5-2017(44)-p.317-324
}

\author{
Baba Md Deros ${ }^{1}$, Dian Darina Indah Daruis ${ }^{2}$, Athirah Liyana Rosly ${ }^{1}$, Ilhami Abd Aziz ${ }^{1}$, Nor Syazwani Hishamuddin ${ }^{1}$, \\ Nur Hidayah Abd Hamid ${ }^{1} \&$ Siti Maisarah Roslin ${ }^{1}$ \\ ${ }^{1}$ Universiti Kebangsaan Malaysia, hjbaba@ukm.edu.my \\ ${ }^{2}$ Universiti Pertahanan Nasional Malaysia
}

\begin{abstract}
This study investigates ergonomic risks faced by manual material handling (MMH) workers performing repetitive loads carrying, holding, lifting, lowering, pushing and pulling activities. A total of $11 \mathrm{MMH}$ workers was recruited to participate in the study. Methods used to collect data were Modified Nordic Questionnaire (MNQ), Rapid Entire Body Assessment (REBA) and NIOSH Lifting Equation. MNQ result showed the $\mathrm{MMH}$ workers' body parts that suffered pain are shoulders (63.6\%), upper back (54.5\%) and lower back (45.4\%). The movements, which recorded high REBA score (i.e. 9) are twisting, lowering and lifting, which is considered as high risk. Based on NIOSH Lifting Equation, the value of RWL for MMH tasks is 15.82 and the lifting index (LI) is 0.73 . The recommended control measures to be implemented in Company $\mathrm{X}$ include to limit the working time, administrative control, training, and reduce the weight of the load carried and lifted by the MMH workers.
\end{abstract}

Keywords: Ergonomics, manual handling, REBA, NIOSH, MNQ

\section{INTRODUCTION}

Normally, a production line in a manufacturing company mainly involves equipment, machinery, and human workers. In heavy industry, innovation in machinery and equipment have substituted human workers to increase safety and productivity. However, in the manufacturing industries, human workers are still required mainly to perform manual handling tasks and processes that are not done by machines. Manual Material Handling (MMH) tasks involve activities such as carrying, lifting, lowering, pushing or moving loads. Repetitive and incorrect MMH techniques could increase the ergonomic risk and have known to caused work-related musculoskeletal disorders (WMSDs). WMSDs are injuries in ligaments, tendons, muscles, nerves and joints (Nurmianto et al. 2015). WMSDs have been a major concern in the manufacturing industry as it affects on workers' productivity, absenteeism, turnover, compensation and work quality (Qutubuddin et al., 2013). However, lack of knowledge and initiative for ergonomics application in manufacturing industry could further increase the chance of exposing the human workers to ergonomic risk factors.

In this study, the three techniques used to estimate the level of workers' discomfort and to assess their ergonomic risks exposure are by using observational techniques and instruments, such as Modified Nordic Questionnaire (MNQ) (Kuorinka et al., 1987), Rapid Entire Body Assessment (REBA) (Hignet \& McAtamney, 2000) and Revised NIOSH Lifting Equation (Waters et al. 1993). Observational techniques are used widely in the majority of companies because, they do not interfere with the work process, convenient and low cost. The natural working position is observed from the angular deviation of employee's body segments (Lasota, 2015). MMH tasks are closely related to musculoskeletal symptoms. According to Gallis (2006), the three factors which contribute towards developing musculoskeletal disorders are the work postures, load, and technique used during performing MMH activities. A study done by Syazwani et al. (2016) indicate long working hours with short rest period is also considered a major ergonomic risk factor. 
Lin \& Radwin (1998) study results showed repetition rate and force used during wrist flexion task using a power grip as risk factors for developing discomfort in hand-task. While historical changes, which demonstrates skeletal tissue, soft tissue and nerves may be sensitive to repetitive movement, and tissue disruption can lead to functional impairment (Revel et al. 1992). Latko et al. (1999) study also found that repetition can be associated with worker-reported discomfort at the wrist, hand and fingers and symptoms consistent with CTS. In other words, workers' performing high repetitive tasks have 2 to 3 times higher risk compared to low repetitive tasks. Thus, it can be concluded that repetitive movement can lead to WMSD if no further action was taken to solve this problem.

Work technique, work organization, and individual characteristics or combined risk factors may influence the musculoskeletal disorder (Gallis, 2006). Workers who exposed to ergonomic risk such as MMH have a high possibility to suffer pain on the entire body parts or muscle pain (Deros et al. 2016). Excessive physical effort can cause back injuries and shoulder injuries (Parejo et al. 2012). Yeung at al. (2002) have found that both lower back and shoulder are the most prevalent locations of musculoskeletal symptoms. This study was conducted to identify working postures practiced among $\mathrm{MMH}$ workers in Company $\mathrm{X}$, to assess their associated ergonomic risks and to determine musculoskeletal discomfort among them.

\section{RESEARCH METHODOLOGY}

This study was conducted at Company X located in Port Klang, Selangor, Malaysia. It was based on workers' complaints of suffering back pain symptoms and problems due to performing MMH activities. Company $\mathrm{X}$ is involved in metallurgy industry which produces sintered metal parts. Powder metal is the raw material for used for manufacturing the sintered metal parts. The powder metal will undergo a few processes to produce sintered automotive part. The processes involved are compacting, sintering, sizing, cutting, treatment, a magnetic crack detector (MCD), sorting, packing and quality check. This study focuses only one section which is a Magnetic Crack Detector (MCD) Process. There are $11 \mathrm{MMH}$ workers working at MCD section. The manufacturing processes involved in manufacturing the sintered metal parts are magnetized, inspection under UV light and demagnetized. The majority of the processes involved manual handling of heavy poly-box, lifting, repetitive motion, twisting, lowering and reaching. The three methods used to identify Work-related Musculoskeletal Disorders (WMSDs) among the MMH workers were MNQ, observation on their working posture using the Rapid Entire Body Assessment (REBA) and NIOSH Lifting equation.

\subsection{Modified Nordic Questionnaires (MNQ)}

MNQ can be used to assessed body parts with WMSDs problem were distributed to the $11 \mathrm{MMH}$ workers in the MCD section. This was done in order to obtain information on their perceptions and level of discomfort they had experienced. To identify the musculoskeletal symptom among MMH workers at MCD section, MNQ was used (Kuorinka et al. 1987). The main purpose of this $\mathrm{MNQ}$ is to identify the prevalence of musculoskeletal symptoms among MCD section MMH workers. $\mathrm{MMH}$ workers were guided on how to answer all the MNQ questions correctly. This MNQ is comprised of a diagram that showed nine body parts: neck, shoulder, upper back, lower back, elbow, hand, thigh, knee and leg as shown in Figure 1. The main purpose is to assist the $11 \mathrm{MMH}$ workers identifying the correct body parts when answering the questions. The numeric scale used ranging from 1 (not painful) until 10 (very painful) can be used to determine the level of WMSDs experienced by the workers.

Figure 1: Nine Body Parts According to MNQ

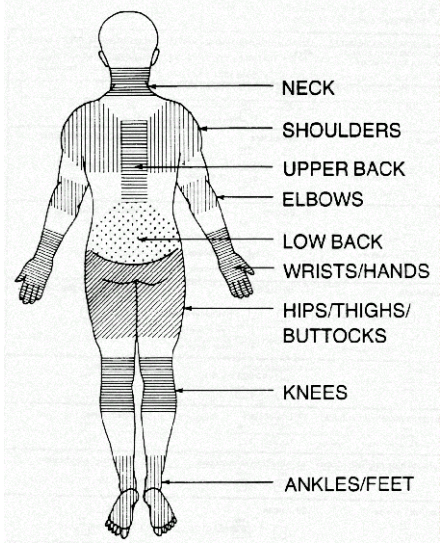




\subsection{Rapid Entire Body Assessment}

Eleven $\mathrm{MMH}$ workers took part in the observation working posture while performing $\mathrm{MMH}$ activities using the Rapid Entire Body Assessment (REBA). The main purpose of this working posture assessment is to associate risk of musculoskeletal injury from the working posture practiced. REBA can be used to identify, assess and evaluate the entire body segments for Workrelated Musculoskeletal Disorders (WMSDs) to entire body segments that include the following body parts: neck, shoulder, upper back, lower back, elbow, hand, thigh, knee, legs, trunk, arms, and wrist. Having done that, overall scores for all body parts were calculated using REBA worksheet and every posture has its scores that need to be assigned. Additional scores for muscles and force also were also calculated to get the final REBA score. The final REBA score will indicate the level musculoskeletal injury risk faced by the $\mathrm{MMH}$ workers.

\subsection{Observation}

During the observation MMH workers were asked to perform their usual activities, it was captured and recorded by using a video camera. This was done for the purpose to properly check and evaluate their daily working postures and to avoid any assessment mistakes that give a false or wrong result. All photos and videos recorded during the observation were utilized to identify ergonomic working postures of the $\mathrm{MMH}$ workers while performing their daily MMH tasks.

\subsection{NIOSH Lifting Equation}

The NIOSH Lifting Equation (Water et al. 1993) is a method to assess risk of low-back disorder with repeated lifting. The value of Recommended Weight Limit (RWL) and the Lifting Index (LI) need to be identified according to the following formula.

\section{RWL = LC $\times$ HM $\times$ VM $\times$ DM $\times A M \times F M$}

where:
LC : Load Constant $(23 \mathrm{~kg})$
HM : Horizontal Multiplier Factor
VM : Vertical Multiplier Factor
DM : Distance Multiplier Factor
AM : Asymetric Multiplier factor
FM : Frequency multiplier Factor
CM : Coupling Multiplier Factor

\section{$\mathbf{L I}=\mathbf{L} / \mathbf{R W L}$}

where:

LI : Lifting Index

L : Actual load weight

RWL: Recommended Weight Limit

\section{RESULTS AND DISCUSSIONS}

\subsection{Modified Nordic Questionnaire (MNQ) Results}

Based on the MNQ given to $\mathrm{MMH}$ workers, it was found many of them had experienced serious pain; $63.6 \%$ at the shoulders, $54.5 \%$ at the upper back, and $45.4 \%$ at the lower back areas. The least pain they suffered is at the knee with only $9.1 \%$ of $\mathrm{MMH}$ workers. Four out of $11 \mathrm{MMH}$ workers have taken medical leave due to the shoulder and back pain in the last of 12 months. This is due to their routine work activity performing MMH of the heavy poly box. The activity involves lifting, lowering, reaching, twisting and repetitive. The percentage of $\mathrm{MMH}$ workers that experience musculoskeletal discomfort at the nine body parts according to the MNQ is shown in Figure 2. 
Figure 2: Musculoskeletal discomfort at 9 body parts according to MNQ

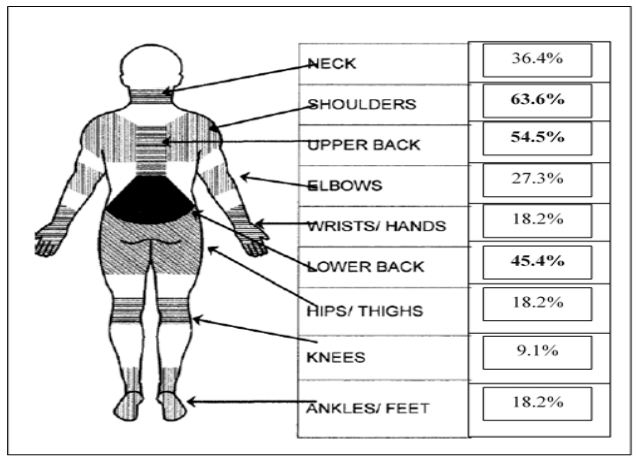

\subsection{REBA Score}

REBA score as tabulated in Table 1 and Figure 3 are expressed on a scale of 1 to 15 . The five categories of scoring used in REBA are from negligible risk until very high risk. Score 1 is categorized as a negligible risk. Score 2 and 3 is categorized as low risk, which may require changes. Score 4 to 7 falls under medium risk, where further investigation and necessary changes are required. While, score 8 to 10 falls into a high risk category, which required further investigation and implementation changes to reduce risk. Score 11 to 15 is considered very high risk and needs to carry out further investigation and implement changes immediately. The three types of postural movements that have REBA score of 9 are twisting, lowering and lifting are considered as high risk. Meanwhile, both repetitive and reaching postural movements have REBA score of 6 and 5 respectively are considered as a medium risk. Figure 4 show the five most common tasks and postures practiced by the MMH workers in MCD section at Company $\mathrm{X}$.

Table 1: Risk Levels of Ergonomic Injury Corresponding to REBA Scores and Indication

\begin{tabular}{lccc}
\hline \multicolumn{1}{c}{ Posture } & REBA Score & Risk Level (REBA) & Action \\
\hline Repetitive & 6 & Medium & Further investigate. Change soon. \\
Lowering & 9 & High & Investigate and implement change. \\
Twisting & 9 & High & Investigate and implement change. \\
Reaching & 5 & Medium & Further investigate. Change soon. \\
Lifting & 9 & High & Investigate and implement change. \\
\hline
\end{tabular}

Figure 3: REBA Score

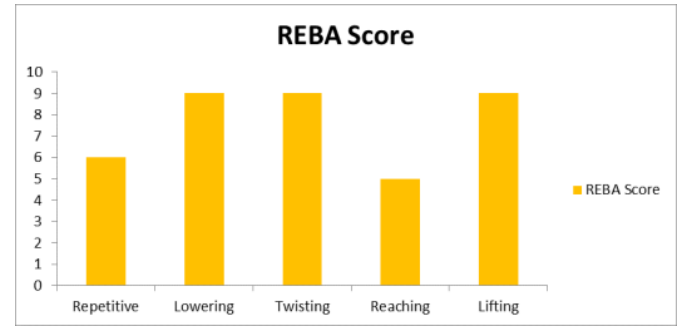


Figure 4: Workers' MMH tasks

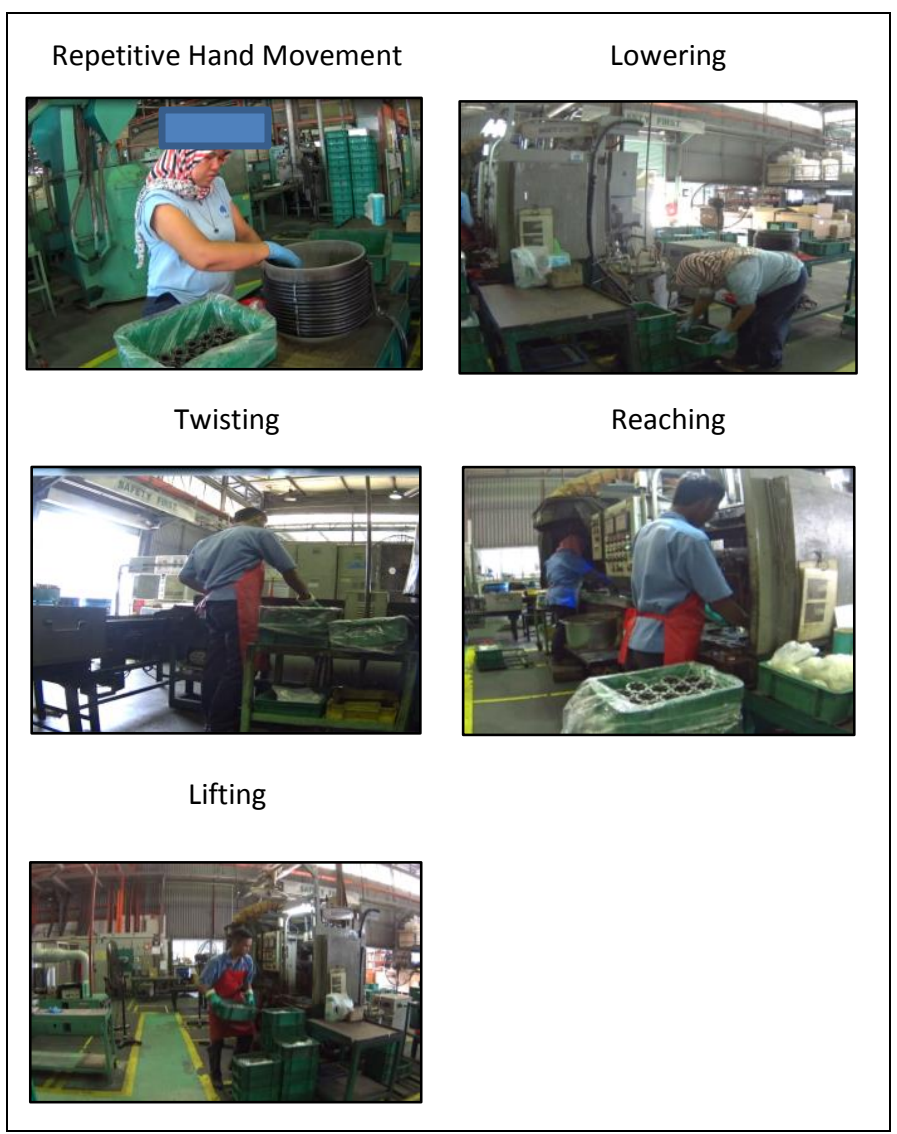

Based on the REBA assessments carried out in Company X, repetitive hand movement falls under medium risk score, which need to take further action and changes in the work posture. Repetitive movements involving the same joints and muscle over and over again when doing the same motion can become hazardous thus increasing the risk of WMSD. Muscles fatigue and joints tiredness due to repetitive works indicate the need to change the work pattern. If no further action was taken, it will cause more pain and inflammation to the muscles and joint such as tendinitis, tenosynovitis and Carpal Tunnel Syndrome (CTS).

REBA result for reaching was classified as medium risk, which means need further investigation and change soon. Compared to the five $\mathrm{MMH}$ activities, reaching is the lowest risk to musculoskeletal disorder. This is due to the work activity is very mild. The worker need to stand for certain period of time and to reach and collect the part, which is located just in front of the MMH worker. There is no twisting or take far object. The worker need to move his hand forward to collect and place the part. The weight of the part is less than $2 \mathrm{~kg}$. Introducing frequent rest time a few minutes every hour can reduce the risk of musculoskeletal disorder.

One of the step to prevent this problem is to limit the time duration by the worker doing the same motion and tasks over and over again. When analyzing specific job for solving ergonomic problems, a few factors such as the weight of object being handle, body position, repetition of certain movement and how worker grip the objects must be taken into considerations. Engineering controls like workstation design, working method, tool and handle design can also be used control this problem. At the same time, the worker should always practice proper working technique, employee conditioning, inspection, feedback and equipment maintenance. In term of administrative control, should reduce the duration, frequency, and severity of exposures to the ergonomic hazard. For example, reducing the number of repetition per hour or provide short rest period to relieve fatigue.

For lowering task movement, after conducting the observation and scoring using REBA, it was classified as high risk. This type of posture or task movement needs to be investigated and implement the required change. Due to forward movement, shoulders, upper and lower back positions are the highest frequency of movements performed by the MMH workers. Workspace design and task requirement are the contributing factors that can lead to good working posture (Zein et al. 2015). At present, the majority of the industrial workplace is poorly designed, and workers needs to adapt with the workspace design to complete the task given. In this study, the lowering posture need the MMH employee to handle a load 
of more than $15 \mathrm{~kg}$. Thus, one of the recommendation is to reduce the load that $\mathrm{MMH}$ employee needs to lower. Company $\mathrm{X}$, management need to provide training and education to $\mathrm{MMH}$ workers on ergonomics posture, when performing lifting and lowering tasks. This would create awareness towards the importance of ergonomics risk factors at the workplace and its association with $\mathrm{MMH}$ employee safety and health.

Based on the REBA result, lifting activity score is 9 . It can be classified as high risk and Company $\mathrm{X}$, management need to conduct a proper investigation and implement the recommended changes to improve their workplace design and to reduce the ergonomic risk factor.

\subsection{NIOSH Lifting Equation}

The highest frequency and severity is lifting and lowering. Lifting and lowering activities involving a load of 11 to $15 \mathrm{~kg}$ per polybox. Based on the NIOSH Lifting Equation, the calculated value of Recommended Weight Limit (RWL) is $15.82 \mathrm{~kg}$, which indicates that the load lifted is acceptable. According to NIOSH Lifiting Equation, if Lifting Index (LI) value is more than 1.0, then the workstation and task should be redesigned. In this case, the calculated Lifting Index (LI) value is 0.73 (i.e. less than 1.0), therefore; there is no need to redesign the workstation, lifting and lowering tasks. However, MMH workers may still suffer from backpain and shoulder pain because they have to manually carry on average 40 - 60 polybox per day and using improper lifting posture.

\section{RECOMMENDATIONS}

\subsection{Administrative Improvements}

Observe how different MMH workers perform the same tasks to get ideas for improving work practices or organizing the work. Administrative improvements that can be carried out, such as: job rotation, can help reduce MMH workers' exposures to risk factors by limiting the amount of time workers spend on "problem jobs". Atishey et al. (2013) have recommended to implement the following adminstrative improvement activities:

a. Alternate heavy tasks with light tasks.

b. Provide variety in jobs to eliminate or reduce repetition (i.e. overuse of the same muscle groups).

c. Adjust work schedules, work pace, or work practices.

d. Provide recovery time (e.g. short rest breaks).

e. Rotate workers through jobs that use different muscles, body parts, or postures.

\subsection{Training}

Training and education are an effective way of increasing awareness on ergonomics issues (Tayyari \& Smith, 1997). In that case, organization need to provide training to workers especially about safety and health matters to ensure that particularly sensitive groups of workers are protected against any dangers which specifically affect them including in relation to the manual handling of loads. The manual handling training needs to be specific to the tasks involved. It should aim to ensure that the employee understands the reasons for doing the job with least risk, can recognize the risks and decide the best way to control the risk and can perform the task in that way. The instructor should ensure that all participants understand and can apply good handling techniques. Manual handling skills and the review of the findings of the risk assessment process should be an integral part of the training programme.

In this case, employers need to engage external competent trainers. Suitable trainers must have knowledge, skill and experience in the subject, have the ability to communicate effectively, are able to give practical demonstrations and have appropriate teaching materials. Besides that, refresher training is also important and will be conducted at intervals not more than every three years and when there is any major change in the work involved or equipment used or when an employee is transferred to another activity requiring different loads to be handled.

\subsection{Reduce Weight of Load}

Reduce the load weight especially if the same operation is repeated many times. As a rough guide, reduce the weights by $30 \%$ if the operation is repeated once or twice a minute, by $50 \%$ if it is repeated 5 - 8 times a minute, and by $80 \%$ when it is repeated more than 12 times a minute. Also, practice team lifting as a temporary measure until a more permanent improvement can be found. If possible, try to find a co-worker of similar height to help with the lift. Team lifting actually can reduce the load in half.

REBA result for twisting posture is 9 which is classified as high risk. Management need conduct an investigation and implement new changes in the workplace design or procedures in order to reduce the ergonomic risk factor. Twisting could cause back injury. Based on the video recording, $\mathrm{MMH}$ workers did a repetitive range action of twisting while moving the 
load to the side. Although the weight load is less than $5 \mathrm{~kg}$, the repetitive motion could cause serious damage to the back tissue. One of the recommendation is to change the working techniques. The Company $\mathrm{X}$ management need to provide training on the proper $\mathrm{MMH}$ techniques of working to avoid twisting by turning the whole body while transferring the load. In addition, workspace design need to be taken into account by ensuring there is enough spaces for workers to turn around when moving the load to avoid twisting.

\subsection{Stretching and Exercise Programs}

In addition, it is recommended that the $\mathrm{MMH}$ workers perform daily body stretching exercises to prevent from them from stiffness and can relax their muscle. This is in-line with Choi \& Woletz (2010) findings that musculoskeletal disorders or injury can be prevented by stretching and exercise programs in different occupations.

\section{CONCLUSION}

Results obtained from the Modified Nordic Questionnaire (MNQ) showed 63.6\% of the MMH workers had experienced serious pain at the shoulders, $54.5 \%$ at the upper back, and $45.4 \%$ at the lower back areas. In the last 12 months, 36\% of $\mathrm{MMH}$ workers have taken medical leave due to the shoulder and back pain problem. Twisting, lowering and lifting tasks postural movements that have REBA score of 9 are considered as high risk. Meanwhile, both repetitive and reaching postural movements have REBA score of 6 and 5 respectively, which are considered as medium risk. For administrative control, Company $\mathrm{X}$ management should reduce the $\mathrm{MMH}$ workers exposures to ergonomic hazard, with respect to duration, frequency and severity. For example, reducing the number of repetition per hour or provide short rest period to relieve fatigue. The pain that the $\mathrm{MMH}$ workers felt on their shoulders, upper back and lower back are due to repetitive motions such as lifting, lowering heavy polybox, and twisting. In short, the ergonomic risk factors in Magnetic Crack Detection section in Company $X$ is high especially that involves lifting, lowering and twisting postures. Company $X$ management needs to carry out investigation, implement changes and improvement in their working procedures, techniques and workspace design to reduce WMSDs risks.

\section{REFERENCES}

Choi, S.D., Woletz, T. 2010. “Do stretching programs prevent work-related musculoskeletal disorders". Journal of Safety, Health and Environmental Research, vol. 6, no. 3, pp. 1-19.

Deros, B. M., Daruis, D.D.I., Ghani, J. A., Salleh, C., Wazir, R. M., Yasim, M. K., Hassan, N.H., Saidi, M. S. 2016. "A case study on manual handling at an electronic component manufacturing company". Malaysian Journal of Public Health Medicine, vol. 1, (Special Issue 1), pp. 16.

Gallis, C. 2006. "Work-Related Prevalence of Musculoskeletal Symptoms among Greek Forest Workers". International Journal of Industrial Ergonomics, vol. 36, no. 8, pp. 731-736.

Hignett, S. \& McAtamney, L. 2000. “Rapid entire body assessment (REBA)”, Applied ergonomics, vol. 31, no. 2, pp. $201-205$.

Kuorinka, I., Jonsson, B., Kilbom, A., Vinterberg, H., Biering-Sørensen, F., Andersson, G., Jørgensen, K. 1987. "Standardised Nordic questionnaires for the analysis of musculoskeletal symptoms", Applied ergonomics, vol. 18, no. 3, pp. $233-237$.

Latko, W.A., Armstrong T.J., Franzblau, A., Ulin, S.S., Werner, R.A., Albers, J.W. 1999. "Cross-Sectional Studies of the relationship between repetitive work and prevalence of upper limb musculoskeletal disorders", American Journal of Industrial Medicine, vol. 36, pp. 248-259.

Lasota, A. M. 2015. "Ergonomic evaluation of physical risk for packing line operators", Logistics and Transport, vol. 26, no. 2, pp. 11-20.

Lin, M.I., Radwin, R.G. 1998. "Agreement between a frequency-weighted filter for continuous biomechanical measurements of repetitive wrist flexion against a load and published pshcophysical data", Ergonomics, vol. 4, pp. 459-475.

Mittal, A., Sharma, H. K., Mittal, K. 2013. "Ergonomic Risk Controls in Construction Industry - A Literature Review", International Journal of Emerging Research Management \& Technology, vol. 2, pp. 28-33.

Nurmianto, E., Ciptomulyono, U., \& Kromodihardjo, S. 2015. "Manual Handling Problem Identification in Mining Industry: An ergonomic perspective", Procedia Manufacturing, vol. 4, pp. 89-97.

Parejo-Moscoso, J. M., Rubio-Romero, J. C., Pérez-Canto, S. 2012. “Occupational Accident Rate in Olive Oil Mills”, Safety Science, vol. 50, no. 2, pp. 285-293.

Qutubuddin, S. M., Hebbal, S. S., Kumar, A. C. S. 2013. “An ergonomic study of work related musculoskeletal disorder risks in Indian Saw Mills", Journal of Mechanical and Civil Engineering, vol. 7, no. 5, pp. 7-13.

Revel, M., Andre-deshays, C., Roudier, R., Roudier, B., Hamard, G., Amor, B. 1992. "Effects of repetitive strains on vertebral end plates in young rats", Clinical orthopaedics and related research, vol. 279, pp. 303-309.

Syazwani, N., Deros, B. M., Ab Rahman, M. N., Ezrin Hani, S., Norani, N., Shamsul Bahri, M. T., Shahriman, A.B., Rambely, A. S. 2016. 
"Ergonomic risk assessment of manual handling tools by oil palm collectors and loaders", Malaysian Journal of Public Health Medicine, vol. 16, pp. 56-60.

Tayyari, F., Smith J.L. 1997. “Occupational Ergonomics Principle And Applications”, Chapman \& Hall (London)Te H.P, \& Kleiner B.H. 2001. New Development Concerning The Occupational Safety And Health Act, vol. 43, Number 1/2 2001.

Waters, T. R., Putz-Anderson, V., Garg, A., Fine, L. J. 1993. "Revised NIOSH equation for the design and evaluation of manual lifting tasks". Ergonomics, vol. 36, no. 7, pp. 749-776.

Yeung, S. S., Genaidy, A., Deddens, J., Alhemood, A., Leung, P. C. 2002. "Prevalence of musculoskeletal symptoms in single and multiple body regions and effects of perceived risk of injury among manual handling workers", Spine, vol. 27, no. 19, pp. 2166-2172.

Zein, R. M., Halim, I., Azis, N. A., Saptari, A., Kamat, S. R. 2015. "A Survey on Working Postures among Malaysian Industrial Workers", Procedia Manufacturing, vol. 2, pp. 450-459. 